\title{
Extrapyramidal Signs and Risk of Progression from Mild Cognitive Impairment to Dementia: A Clinical Research Center for Dementia of South Korea Study
}

\author{
Woojae Myung ${ }^{1 *}$, Jin Hong Park ${ }^{2 \star}$, Sook-Young $\mathrm{Woo}^{3}$, Seonwoo Kim ${ }^{3}$, Sang Ha Kim², Jae Won Chung ${ }^{2}$, \\ Hyo Shin Kang ${ }^{4}$, Shinn-Won Lim ${ }^{2,4,5}$, Junbae $\mathrm{Choi}^{2}$, Duk L. Na ${ }^{6}$, Seong Yoon Kim ${ }^{7}$, Jae-Hong Lee, \\ Seol-Heui Han ${ }^{9}$, Seong Hye Choi ${ }^{10}$, Sang Yun Kim ${ }^{11}$, Bernard J. Carroll ${ }^{12}$, and Doh Kwan Kim ${ }^{2 凶}$ \\ ${ }^{1}$ Department of Psychiatry, CHA Bundang Medical Center, CHA University, Seongnam, Republic of Korea \\ ${ }^{2}$ Department of Psychiatry, Samsung Medical Center, Sungkyunkwan University School of Medicine, Seoul, Republic of Korea \\ ${ }^{3}$ Biostatistical Team, Samsung Biomedical Research Institute, Seoul, Republic of Korea \\ ${ }^{4}$ Center for Clinical Research, Samsung Biomedical Research Institute, Seoul, Republic of Korea \\ ${ }^{5}$ Department of Health Sciences and Technology, SAIHST, Sungkyunkwan University, Seoul, Republic of Korea \\ ${ }^{6}$ Department of Neurology, Samsung Medical Center, Sungkyunkwan University School of Medicine, Seoul, Republic of Korea \\ ${ }^{7}$ Department of Psychiatry, Asan Medical Center, University of Ulsan College of Medicine, Seoul, Republic of Korea \\ ${ }^{8}$ Department of Neurology, Asan Medical Center, University of Ulsan College of Medicine, Seoul, Republic of Korea \\ 9Department of Neurology, Konkuk University School of Medicine, Seoul, Republic of Korea \\ ${ }^{10}$ Department of Neurology, Inha University School of Medicine, Incheon, Republic of Korea \\ ${ }^{11}$ Department of Neurology, Seoul National University Bundang Hospital, Seongnam, Republic of Korea \\ ${ }^{12}$ Department of Psychiatry and Behavioral Sciences, Duke University Medical Center, Durham, NC, USA
}

Objective Extrapyramidal signs (EPS) are common in patients with mild cognitive impairment (MCI). However, few studies have assessed the effect of EPS on the clinical course of MCI. We aimed to evaluate whether patients with EPS show more frequent progression from MCI to Alzheimer's disease (AD) and to other types of dementia.

Methods Participants ( $\mathrm{n}=882$ ) with MCI were recruited, and were followed for up to 5 years. The EPS positive group was defined by the presence of at least one EPS based on a focused neurologic examination at baseline.

Results A total of 234 converted to dementia during the follow-up period. The risk of progression to AD was lower in the patients with EPS after adjusting for potential confounders [hazard ratio $(\mathrm{HR})=0.70,95 \%$ confidence interval $(\mathrm{CI})=0.53-0.93$, $\mathrm{p}=0.01]$. In contrast, the patients with EPS had a six-fold elevated risk of progression to dementia other than $\mathrm{AD}(\mathrm{HR}=6.33,95 \% \mathrm{CI}=2.30-17.39$, $\mathrm{p}<0.001)$.

Conclusion EPS in patients with MCI is a strong risk factor for progression of MCI to non-Alzheimer dementia. The careful neurologic examination for EPS in patients with MCI can yield important clinical information for prognosis.

Psychiatry Investig 2017;14(6):754-761

Key Words Alzheimer disease, Mild cognitive disorder, Extrapyramidal signs, Progression.

\section{INTRODUCTION}

Mild cognitive impairment (MCI) is a clinical entity de-

Received: June 21, 2016 Revised: March 15, 2017

Accepted: March 23, 2017 Available online: August 29, 2017

$\triangle$ Correspondence: Doh Kwan Kim, MD, PhD

Department of Psychiatry, Samsung Medical Center, Sungkyunkwan University School of Medicine, 81 Irwon-ro, Gangnam-gu, Seoul 06351, Republic of Korea Tel: +82-2-3410-3582, Fax: +82-2-3410-0941, E-mail: paulkim@skku.edu

*These authors contributed equally to this work.

(a) This is an Open Access article distributed under the terms of the Creative Commons Attribution Non-Commercial License (http://creativecommons.org/licenses/by$\mathrm{nc} / 4.0$ ) which permits unrestricted non-commercial use, distribution, and reproduction in any medium, provided the original work is properly cited. fined as abnormal cognitive function relative to age and education, with preserved activities of daily living. ${ }^{1}$ Based on several longitudinal studies, ${ }^{2-5} \mathrm{MCI}$ has attracted much attention as a prodromal phase to dementia. The prevalence of MCI is estimated at between $10-20 \%$ in elderly populations ${ }^{6-8}$ and the annual progression rates to Alzheimer's disease $(\mathrm{AD})$ is estimated at approximately $5-10 \%$ in a meta-analysis. ${ }^{9}$ Female gender, older age, low educational level, diabetes mellitus (DM), subclinical depression, white matter hyperintensities (WMH), and presence of the APOE $\varepsilon 4$ allele are reported as risk factors for progression from $\mathrm{MCI}$ to incident demen- 
tia. ${ }^{2-4,10-12}$ However, little has been known about focal neurological signs as a risk factor for the progression from MCI to incident dementia.

Extrapyramidal signs (EPS) are common in elderly people without any diagnosed neurological disease and also in individuals with $\mathrm{MCI} .{ }^{13}$ These neurological signs include rigidity, resting tremor, impaired gait and balance, and they are readily observed in the clinical setting without expensive laboratory equipment. For two decades, multiple studies have revealed that $\mathrm{EPS}$ in $\mathrm{AD}$ is related to functional impairment, ${ }^{14,15}$ faster cognitive decline, ${ }^{16}$ greater risk of institutionalization ${ }^{17}$ and higher mortality. ${ }^{18}$ Recent population based prospective studies have demonstrated that EPS in nondemented elderly subjects are associated with incident dementia. ${ }^{19,20}$ However, few studies have assessed the clinical impact of EPS in MCI, especially in terms of progression to dementia. Moreover, as far as we know there is no study that examined the effect of EPS on the progression to dementia other than $\mathrm{AD}$. In this study, we investigated the role of EPS as a risk factor for the progression from MCI to $\mathrm{AD}$ and to other types of dementia in a large cohort collected through a coordinated national clinical network.

\section{METHODS}

\section{Subjects}

This study was conducted as a part of the Clinical Research Center for Dementia of South Korea (CREDOS) study, an ongoing, prospective, nationwide, hospital-based multi-center study with fifty-six participating hospitals. ${ }^{21}$

All patients were diagnosed with MCI and they had at least one longitudinal clinical review after baseline. The criteria for MCI in the CREDOS study ${ }^{22}$ are as follows: 1) presence of concern about a change in cognition; 2) intact function in Activities of Daily Living except performing complex functional tasks; 3 ) objective cognitive impairment (at least - 1.0 standard deviation below age-and education-adjusted norms) in more than one cognitive domain on standardized neuropsychological testing ${ }^{23}$; 4) Clinical Dementia Rating (CDR) of $0.5,{ }^{24}$ and 5) not demented according to Diagnostic and Statistical Manual of Mental Disorders (DSM)-IV-TR criteria. ${ }^{25}$ All subjects had to have a reliable informant familiar with the patient's daily activities. None of the subjects presented any of the following exclusion criteria: 1) history of significant hearing or visual impairment rendering participation in the interview difficult; 2) neurological disorders (e.g., territorial infarction, intracranial hemorrhage, brain tumor, hydrocephalus, multiple scle-

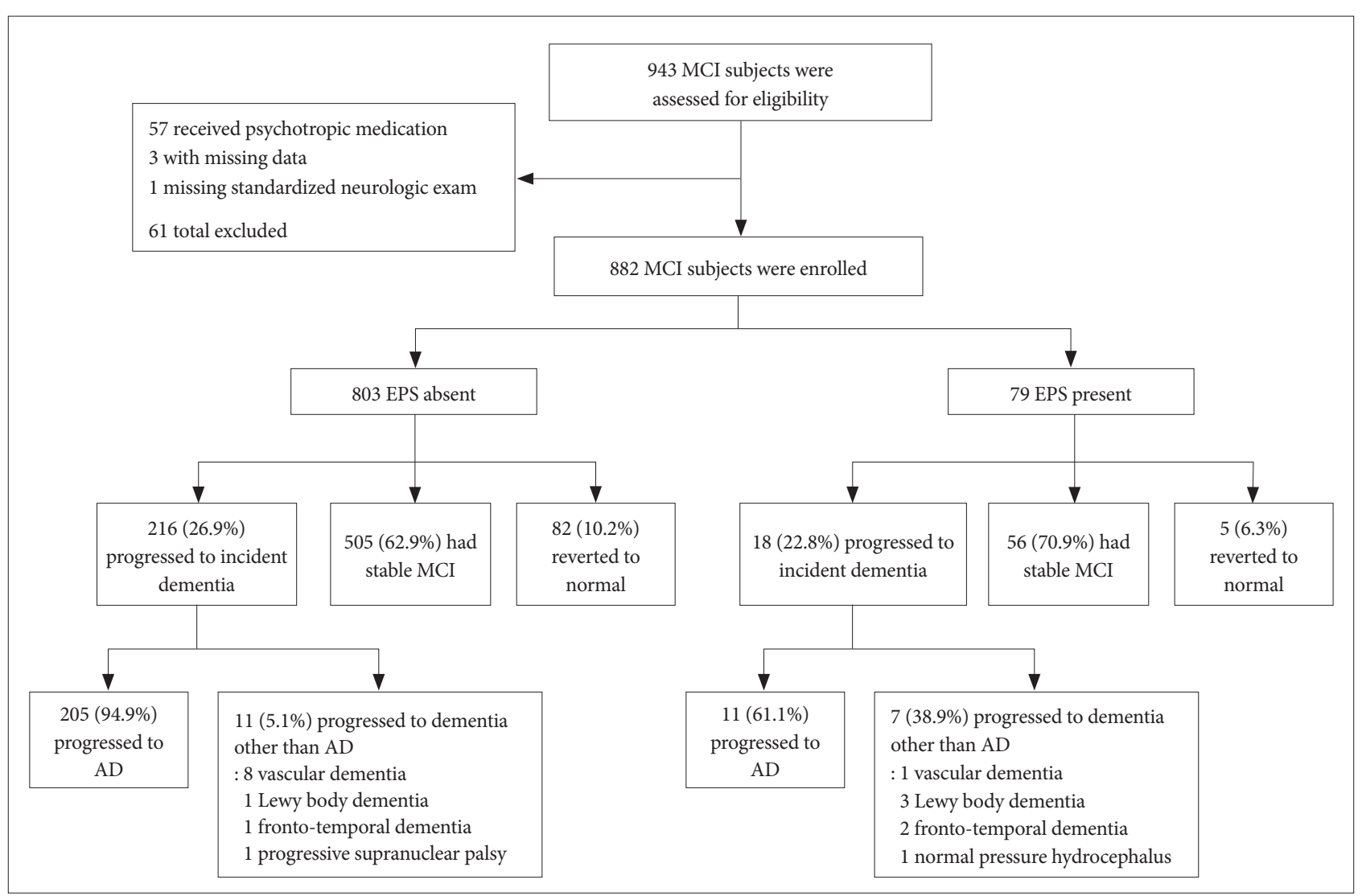

Figure 1. Flow of participants in the study. MCl: mild cognitive impairment, EPS: extrapyramidal symptom, AD: Alzheimer's disease. 
rosis, Parkinson disease, Huntington's disease, tardive dyskinesia); 3 ) major psychiatric disorders (e.g., schizophrenia, mental retardation, mania); and 4) physical illnesses that could interfere with the clinical study (e.g., severe cardiac, respiratory diseases, uncontrolled diabetes, malignancy). In addition, absence of current psychotropic drug use was required in order to exclude drug-induced EPS.

There were $943 \mathrm{MCI}$ subjects drawn from the CREDOS cohort (November 2005 to May 2012) and screened for eligibility. Of these, 57 patients with current psychotropic drug use, three patients with missing data, and 1 patient who did not receive a standardized neurological examination were excluded (Figure 1). The remaining $882 \mathrm{MCI}$ subjects were followed for up to 5 years $[1.44(1.02,2.24)]$. The study protocol was approved by the Institutional Review Boards of participating centers. Informed consent was provided by all subjects and family informants.

\section{Clinical evaluation}

We evaluated all participants with a complete medical interview, physical and neurological examinations, and neuropsychological tests. We assessed routine laboratory tests at baseline, including complete blood counts, blood chemistry profiles, vitamin $\mathrm{B}_{12} /$ folate levels, syphilis serology, and thyroid function tests. Brain magnetic resonance imaging (MRI) scans were obtained in all cases at baseline, with transaxial $\mathrm{T}_{2}, \mathrm{~T}_{1}$-weighted scans, and fluid-attenuated inversion recovery slices. Scans were rated for white matter hyperintensity (WMH) on a rating scale developed for CREDOS. ${ }^{26,27}$ Patients were classified into two groups (mild vs. moderate or severe) based on their WMH around the lateral ventricles or in deep white matter. We classified amnestic MCI (aMCI) based on memory function, which was considered abnormal when the performance in the delayed recall item of either the Seoul Verbal Learning Test (SVLT) or the Rey Complex Figure Test (RCFT) was lower than -1.0 standard deviation compared to age and education matched norms. ${ }^{28}$

In addition, we used the Korean version of the Mini-Mental State Examination (K-MMSE) to assess baseline global cognitive function. ${ }^{29}$ Depressive symptoms were assessed using the 15-item Geriatric Depression Scale (GDS-15). ${ }^{30}$ Neurological examination was conducted by physicians who followed a standardized protocol for identifying EPS. Patients were classified into the EPS group if they had at least one of the following 11 signs: resting tremor, rigidity (upper, lower, or axial), bradykinesia, decreased arm swing, stooped posture, short step gait, festination, shuffling, or impaired pivot turning. ${ }^{15}$ All psychometric tests were scheduled at 6-month intervals for as long as each case remained in follow-up.

\section{Diagnosis of dementia}

Dementia diagnoses and specific cause assignments were made in accordance with DSM-IV-TR criteria ${ }^{25}$ and required objective deficits on neuropsychological testing as well as impairment in activities of daily living. Additionally, specific diagnostic criteria were used for dementia classification. A diagnosis of probable $\mathrm{AD}$ was adapted from the criteria from the National Institute of Neurological and Communicative Diseases and Stroke-Alzheimer Disease and Related Disorders Association (NINCDS-ADRDA).$^{31}$ Subcortical vascular dementia was diagnosed in accordance with National Institute of Neurological Disorders and Stroke-Association Internationale pour la Recherche et l'Enseignement en Neurosciences (NINDS-AIREN) criteria $^{32}$ and imaging criteria proposed by Erkinjuntti. ${ }^{33}$ Onset of dementia was defined as the date on which the clinical symptoms and neuropsychological tests first allowed the diagnosis of dementia to be made. Only one diagnosis of dementia was allowed for each subject. Patients with mixed dementia were classified as one diagnosis according to the judgment of the clinicians.

\section{Statistical analysis}

Continuous variables and categorical variables are presented as median (interquartile range) and frequency (proportion), respectively. The chi-square test and Fisher's exact test were used to compare categorical variables and the Wilcoxon rank-sum test was used to compare continuous variables between the EPS and non-EPS groups. We used Cox regression for competing risk to analyze the effect of EPS on $\mathrm{AD}$, treating dementia other than $\mathrm{AD}$ as a competing risk, and then on dementia other than $\mathrm{AD}$, treating $\mathrm{AD}$ as a competing risk. The time variable was defined as the interval from MCI diagnosis to probable $\mathrm{AD}$ onset, or to onset of dementia other than AD. Durations at risk were estimated from baseline to the last follow-up or to a diagnosis of dementia. The assumptions of proportional hazards were confirmed by the residuals-based test. ${ }^{34}$ In addition, we conducted Cox regression without consideration of competing risk as a sensitivity analysis. Results were considered statistically significant at the two-tailed threshold of $\mathrm{p}<$ 0.05. R 3.1.0 public statistics software (http://www.r-project.org) was used for all statistical analyses.

\section{RESULTS}

\section{Subject characteristics}

The clinical and demographic characteristics of the patients at baseline are shown in Table 1 . The proportion of patients with EPS was 9.0\% (79/882). We recruited 298 male patients and 584 female patients, the male to female ratio was $0.51 \mathrm{sim}$ ilar results in recent population study in Korean elderly. ${ }^{35}$ The 
Table 1. Clinical and demographic characteristics at baseline*

\begin{tabular}{|c|c|c|c|c|}
\hline Variables & Total $(\mathrm{N}=882)$ & Non-EPS group $(\mathrm{N}=803)$ & EPS group $(\mathrm{N}=79)$ & $\mathrm{p}$ \\
\hline Gender, male $(\%)^{\dagger}$ & $298(33.8)$ & $271(33.8)$ & $27(34.2)$ & 0.94 \\
\hline Age $(\text { year })^{\ddagger}$ & $71(66,76)$ & $71(66,76)$ & $73(70,77)$ & 0.01 \\
\hline Education (year) $)^{\ddagger}$ & $6.5(5,12)$ & $7(5,12)$ & $6(3,11)$ & 0.05 \\
\hline Diabetes $(\%)^{\dagger}$ & $190(21.5)$ & $173(21.5)$ & $17(21.5)$ & 1.00 \\
\hline Hypertension (\%) ${ }^{\dagger}$ & 449 (50.9) & $408(50.8)$ & $41(51.9)$ & 0.85 \\
\hline K-MMSE score s $^{\ddagger}$ & $25(23,27)$ & $25(23,27)$ & $25(22,27)$ & 0.09 \\
\hline GDS-15 score ${ }^{\ddagger}$ & $5(3,10)$ & $5(3,10)$ & $7(4,10)$ & 0.03 \\
\hline White matter hyperintensity (moderate or severe) $(\%)^{\dagger}$ & $226(25.6)$ & $196(24.4)$ & $30(38.0)$ & $<0.01$ \\
\hline Amnestic MCI $(\%)^{\dagger}$ & $727(82.4)$ & $666(82.9)$ & $61(77.2)$ & 0.20 \\
\hline APOE $\varepsilon 4$ carrier $(\%)^{\dagger \S}$ & $196(38.4)$ & $189(39.4)$ & $7(23.3)$ & 0.08 \\
\hline
\end{tabular}

${ }^{*}$ continuous variables and categorical variables are presented as median (interquartile range) and frequency (proportion), respectively, ${ }^{\dagger} \mathrm{chi}-$ square test was used, ${ }^{\ddagger}$ wilcoxon rank-sum test was used, §for logistic reasons, only 510 patients (57.8\%) were genotyped for APOE gene. MCI: mild cognitive impairment, EPS: extrapyramidal signs, K-MMSE score: Korean Mini Mental State Examination score, GDS-15: 15-item Geriatric Depression Scale

Table 2. Univariate analysis: Cox regression for competing risk for EPS in individuals with $\mathrm{MCl}$ who progressed to dementia

\begin{tabular}{|c|c|c|c|c|c|c|}
\hline \multirow{2}{*}{ Variables } & \multicolumn{3}{|c|}{$\mathrm{AD}(\mathrm{N}=216)$} & \multicolumn{3}{|c|}{ Dementia other than $\mathrm{AD}(\mathrm{N}=18)$} \\
\hline & HR & $95 \% \mathrm{CI}$ & $\mathrm{p}$ & $\mathrm{HR}$ & $95 \% \mathrm{CI}$ & $\mathrm{p}$ \\
\hline EPS & 0.48 & $0.26-0.90$ & 0.02 & 6.48 & $2.52-16.7$ & $<0.0001$ \\
\hline Gender, male & 0.09 & $0.65-1.14$ & 0.31 & 1.30 & $0.51-3.34$ & 0.58 \\
\hline Age & 1.05 & $1.02-1.07$ & $<0.0001$ & 1.04 & $0.98-1.11$ & 0.18 \\
\hline Education & 1.01 & $0.98-1.03$ & 0.68 & 1.01 & $0.92-1.11$ & 0.79 \\
\hline Diabetes mellitus & 0.98 & $0.71-1.37$ & 0.92 & 0.75 & $0.28-2.58$ & 0.65 \\
\hline Hypertension & 0.80 & $0.62-1.04$ & 0.10 & 0.94 & $0.37-2.35$ & 0.89 \\
\hline K-MMSE score & 0.88 & $0.85-0.91$ & $<0.0001$ & 0.96 & $0.87-1.06$ & 0.41 \\
\hline GDS-15 & 0.98 & $0.95-1.02$ & 0.32 & 1.03 & $0.92-1.15$ & 0.66 \\
\hline $\begin{array}{l}\text { White matter hyperintensity } \\
\text { (moderate or severe) }\end{array}$ & 1.35 & $1.01-1.82$ & 0.05 & 1.95 & $0.75-5.07$ & 0.17 \\
\hline Amnestic MCI & 2.65 & $1.60-4.38$ & $<0.001$ & 3.39 & $0.45-25.70$ & 0.24 \\
\hline
\end{tabular}

MCI: mild cognitive impairment, AD: Alzheimer's disease, HR: hazard ratio, CI: confidence interval, EPS: extrapyramidal signs, K-MMSE score: Korean Mini Mental State Examination score, GDS-15: 15-item Geriatric Depression Scale

median age was $71(66,76)$. Patients with EPS were older and had higher GDS-15 scores than the patients without EPS ( $\mathrm{p}<$ 0.05). No significant differences were found in education, MMSE score, or the proportions with diabetes or hypertension. The prevalence of WMH was significantly higher in the EPS group (38.0\% vs. $24.4 \%, \mathrm{p}<0.01)$. For logistic reasons, only $510 \mathrm{pa}-$ tients (57.8\%) were genotyped for APOE gene. The APOE $\varepsilon 4$ carrier status was not associated with EPS. In the EPS group, the median number of EPS was $2(1,3)$, and the most frequent symptom was rigidity of upper arms $(45.6 \%, 36 / 79)$.

\section{Longitudinal progression of subjects}

Among the 882 patients with MCI (Figure 1), 803 patients exhibited no EPS. Of these, 216 (26.9\%) converted to dementia, 505 (62.9\%) had stable MCI, and $82(10.2 \%)$ reverted to a normal state. Among the 216 patients without EPS who progressed to incident dementia, 205 subjects (94.9\%) were classified as $\mathrm{AD}$, and 11 subjects (5.1\%) were diagnosed with other dementia than $\mathrm{AD}$ (8 vascular dementia, 1 Lewy body dementia, 1 Fronto-temporal dementia, and 1 progressive supranuclear palsy). Among the 79 patients with EPS, 18 (22.8\%) converted to dementia, 56 (70.9\%) remained in the range of MCI, and $5(6.3 \%)$ reverted to a normal state. Among the 18 patients in the EPS positive group who progressed to dementia, 11 subjects (61.1\%) were diagnosed with $\mathrm{AD}$, and 7 (38.9\%) progressed to dementia other than $\mathrm{AD}$ (1 vascular dementia, 3 Lewy body dementia, 2 Fronto-temporal dementia, and 1 normal pressure hydrocephalus).

There was no significant difference in follow-up interval between two groups $(\mathrm{p}=0.34$ ). The observed conversion rate to $\mathrm{AD}$ 
was significantly associated with the presence of EPS [EPS negative group: 205/803 (25.5\%); EPS positive group: 11/79 (13.9\%), $\mathrm{p}=0.03$ ]. In addition, the association between EPS and the observed conversion rate to dementia other than $\mathrm{AD}$ also was significant [EPS negative group: 11/803 (1.4\%); EPS positive group: $7 / 79$ (8.9\%), $\mathrm{p}<0.001]$.

\section{Risk factors for progression from MCI to dementia}

Table 2 presents the results of univariate analyses of competing risks regression for $\mathrm{AD}$ and for dementia other than $\mathrm{AD}$. Patients with EPS, younger age, higher K-MMSE score, mild $\mathrm{WMH}$ or non-amnestic MCI were less likely to progress from $\mathrm{MCI}$ to $\mathrm{AD}$ in univariate analyses $(\mathrm{p}<0.05)$. In addition, patients with EPS were more likely to progress from MCI to dementia other than $\mathrm{AD}(\mathrm{p}<0.0001)$.

From multivariable analysis (Table 3), patients with EPS had a significantly lower HR for AD progression $[\mathrm{HR}=0.70$,
$95 \%$ confidence interval $(\mathrm{CI})=0.53-0.93, \mathrm{p}=0.01]$ after controlling gender, age, education, DM, HTN, K-MMSE score, GDS-15, WMH and amnestic MCI. Figure 2A showed greater hazard for $\mathrm{AD}$ among individuals with MCI without EPS. In contrast, a significantly elevated HR was observed in those with EPS for progression to dementia other than $\mathrm{AD}(\mathrm{HR}=6.33$, $95 \% \mathrm{CI}=2.30-17.39, \mathrm{p}<0.001$ ) (Table 3, Figure 2B). The effects of EPS on $\mathrm{AD}$ and dementia other than $\mathrm{AD}$ progression was preserved in sensitivity analyses without consideration of competing risks $(\mathrm{HR}=0.52,95 \% \mathrm{CI}=0.28-0.96, \mathrm{p}=0.04$ for $\mathrm{AD}$ progression; $\mathrm{HR}=6.00,95 \% \mathrm{CI}=2.28-15.78, \mathrm{p}<0.0001$ for progression to dementia other than $\mathrm{AD}$ ). Additionally, the number of EPS symptom, as a continuous variable, was significantly associated with progression to dementia. As the number of EPS symptom increased, the risk of progression to $\mathrm{AD}$ decreased ( $\mathrm{HR}=0.70,95 \% \mathrm{CI}=0.53-0.93, \mathrm{p}=0.01$ for $\mathrm{AD}$ progression $)$, while the risk of progression to dementia other than $\mathrm{AD}$ in-

Table 3. Multivariable analysis: Cox regression for competing risk for EPS in individuals with $\mathrm{MCl}$ who progressed to dementia

\begin{tabular}{|c|c|c|c|c|c|c|}
\hline \multirow{2}{*}{ Variables } & \multicolumn{3}{|c|}{$\mathrm{AD}(\mathrm{N}=216)$} & \multicolumn{3}{|c|}{ Dementia other than $\mathrm{AD}(\mathrm{N}=18)$} \\
\hline & HR & $95 \% \mathrm{CI}$ & $\mathrm{p}$ & HR & $95 \% \mathrm{CI}$ & $\mathrm{p}$ \\
\hline EPS & 0.70 & $0.53-0.93$ & 0.01 & 6.33 & $2.30-17.39$ & $<0.001$ \\
\hline Gender, male & 0.76 & $0.55-1.05$ & 0.09 & 1.16 & $0.45-3.02$ & 0.76 \\
\hline Age & 1.03 & $1.01-1.06$ & $<0.01$ & 1.03 & $0.96-1.11$ & 0.44 \\
\hline Education & 1.08 & $1.04-1.11$ & $<0.0001$ & 1.02 & $0.93-1.13$ & 0.65 \\
\hline Diabetes & 1.12 & $0.82-1.54$ & 0.48 & 0.75 & $0.22-2.62$ & 0.65 \\
\hline Hypertension & 0.72 & $0.55-0.94$ & 0.02 & 0.88 & $0.33-2.35$ & 0.80 \\
\hline K-MMSE score & 0.84 & $0.8-0.88$ & $<0.0001$ & 0.97 & $0.86-1.09$ & 0.57 \\
\hline GDS-15 & 1.00 & $0.97-1.03$ & 0.78 & 1.02 & $0.89-1.17$ & 0.75 \\
\hline White matter hyperintensity (moderate or severe) & 1.17 & $0.86-1.6$ & 0.33 & 1.55 & $0.55-4.41$ & 0.41 \\
\hline Amnestic MCI & 2.09 & $1.26-3.45$ & $<0.01$ & 3.67 & $0.49-27.75$ & 0.21 \\
\hline
\end{tabular}

MCI: mild cognitive impairment, AD: Alzheimer's disease, HR: hazard ratio, CI: confidence interval, EPS: extrapyramidal signs, K-MMSE score: Korean Mini Mental State Examination score, GDS-15: 15-item Geriatric Depression Scale
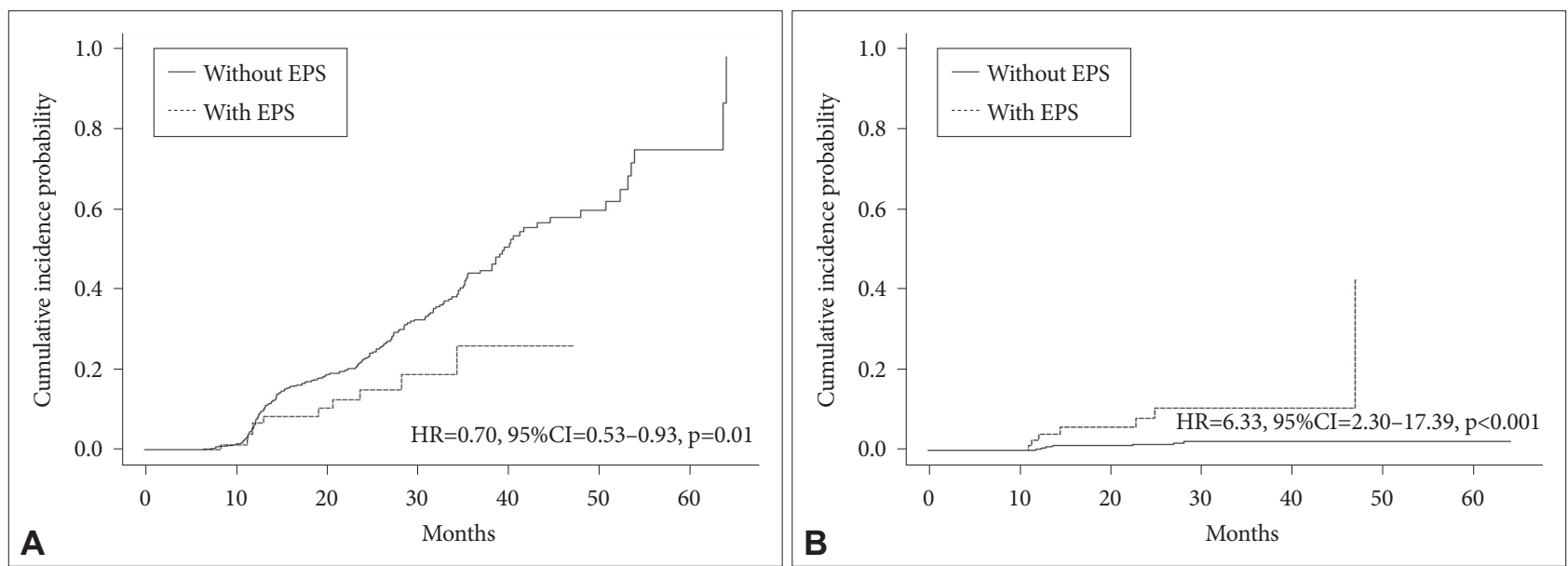

Figure 2. Cumulative incidence probability curves for dementia according to EPS, estimated by competing risks regression model. A: Progressed to Alzheimer disease from $\mathrm{MCl}$. B: Progressed to dementia other than AD from MCl. EPS: extrapyramidal symptom, HR: hazard ratio, $\mathrm{Cl}$ : confidence interval. 
creased $(\mathrm{HR}=1.58,95 \% \mathrm{CI}=1.21-2.06, \mathrm{p}<0.001$ for progression to dementia other than $\mathrm{AD})$.

In addition, for progression to $\mathrm{AD}$ significantly higher HRs were observed for increasing age and education, absence of hypertension, and lower K-MMSE score (Table 3). Amnestic $\mathrm{MCI}$ also was associated with progression to $\mathrm{AD}$. However, these variables conferred no significant risk for progression to dementia other than AD.

\section{DISCUSSION}

In this study, we investigated the effects of EPS on progression to dementia in a prospective cohort of individuals with MCI examined for up to 5 years. We found that risk of progression to $\mathrm{AD}$ was decreased in the patients with EPS, whereas these patients had a six-fold elevated risk of progression to dementia other than AD.

Previous studies have shown different results. Wilson et al. ${ }^{20}$ reported that baseline EPS were associated with incident $\mathrm{AD}$ in the non-demented elderly. Louis et al. ${ }^{19}$ also reported a similar finding that EPS are a risk factor for developing dementia in elderly subjects without current cognitive impairment or Parkinson disease. We can suggest several reasons for such discrepancies. The first is different subject characteristics between previous studies and the present study. Although some patients with MCI may have been included, these two previous studies mainly included normal elderly subjects. Another previous study that investigated the association of EPS with progression to dementia in individuals with MCI reported inconsistent results. Israeli-Korn et al. ${ }^{36}$ reported that EPS were not associated with progression to dementia in individuals with MCI. Unlike our results, this study also found no reduction of risk for progression to $\mathrm{AD}$ associated with EPS. However their sample size was too small to detect a significant effect of EPS $(\mathrm{n}=111)$.

Another plausible reason for the lack of agreement between our results and previous reports is the different analytic method for dealing with dementia other than AD. Previous studies did not consider the competing risk of dementia other than $\mathrm{AD}$; they simply excluded other forms of dementia in their analysis. Assistance by brain imaging for the differential diagnosis in our study could be another reason for the discrepancy. In previous studies, brain imaging was not routinely performed. Wilson et al. ${ }^{20}$ reported that, among all cases progressing to dementia, only five persons developed dementia other than $\mathrm{AD}$ whereas 114 persons developed $\mathrm{AD}$. This proportion (5/ $119,4.2 \%)$ is considerably lower than in the present study $(18 / 234,7.7 \%)$. There is a possibility that some patients with other forms of dementia were misdiagnosed as $\mathrm{AD}$ in their study.
The differences in recruitment settings between previous studies and the present study should be noted. It is known that the progression rate is higher in studies that recruit subjects from memory clinics than from community-based samples. The progression ratio was $26.5 \%$ (234/882) in this study from the CREDOS memory clinics, which is higher than those in two previous community cohorts with comparable followup duration (13.8\% for 4.6 years of mean follow-up period ${ }^{20}$ and $21.8 \%$ for 5.6 years of mean follow-up period ${ }^{19}$ ). In addition, majority of cases progressed to $\mathrm{AD}(216 / 234,93 \%)$ with small proportion of dementia other than $\mathrm{AD}$. This contrasts with the proportion of dementia other than $\mathrm{AD}$ in previous studies. ${ }^{9,37}$ We excluded individuals with MCI who had vascular risk factor (e.g., territorial infarction) in CREDOS study. While this does not invalidate our results, it may account for the differences between our results and other studies. ${ }^{38}$

In contrast with the result of progression to $\mathrm{AD}$, individuals with MCI with EPS had a 6-fold higher risk for progression to dementia other than $\mathrm{AD}$. There are several reasons to suggest that EPS may share similar pathologies with dementia other than AD. EPS are associated with vascular risk factors and white matter changes ${ }^{37}$ which are more frequent in vascular dementia than in AD. Neural loss and alpha-synuclein pathology in the substantia nigra have been found in patients with both EPS ${ }^{39}$ and dementia with Lewy bodies. ${ }^{40}$ Moreover, parkinsonian features are commonly observed in progressive supranuclear palsy and normal pressure hydrocephalus. ${ }^{41}$ Therefore, EPS in MCI could be potential indicators of dementia other than $\mathrm{AD}$. Larger studies will be helpful to confirm our results and to reveal underlying mechanisms in specific forms of non-AD dementia.

In the normal population, it is widely known that low educational level is a risk factor for $\mathrm{AD}$, and high education level has a protective effect in cognition. However, in our sample, a higher education level was positively associated with progression to $\mathrm{AD}$. This paradoxical finding could be explained by the concept of cognitive reserve. ${ }^{42}$ Those with higher cognitive reserve (high education level) can tolerate more pathology so the time point at which cognitive functions begin to be impaired will be delayed in comparison to those with lower cognitive reserve (low education level). However, they showed more rapid cognitive decline when the pathology is more advanced. ${ }^{43}$ In addition, Ye et al. ${ }^{44}$ reported that the protective effects of education against cognitive decline disappear in latestage MCI. This finding gives a possible reason for the paradoxical association of higher education with progression to $\mathrm{AD}$ in our results.

Our study has several strengths. First, we included a relatively large sample of more than 900 patients with MCI in multicenter clinics. Second, we considered various confound- 
ing factors identified from previous research. Because brain MRI images of all subjects were assessed at the baseline, we could control on WMH as a covariate. ${ }^{45}$ We also controlled for severity of depressive symptoms assessed by the GDS-15. Third, we employed Cox regression for analysis of competing risk. This statistical analysis was developed for situations in which observation of one outcome may obscure observation of the other. In our study, the effect of EPS on AD could be obscured by the incidence of dementia other than $\mathrm{AD}$ and vice versa. Ignorance of such competing events results in an overestimate of the cumulative incidences. ${ }^{46}$ Competing risks regression has been used infrequently in dementia progression studies. Our study may direct attention to this statistical approach in this field.

There are several limitations that should be mentioned. First, we did not evaluate EPS by using a scale of severity. Thus, we could not analyze the association between severity of EPS and dementia progression in individuals with MCI. Alternatively, we found the relationship between number of EPS symptom and progression to dementia. Second, it is difficult to draw a line between $\mathrm{AD}$ versus vascular dementia in clinical setting. Although, we assessed brain MRI images in all subjects, there is possibility of misclassification. Third, we could not obtain APOE $\varepsilon 4$ allele status from all of the participants (Table 1), as was the case in other previous studies. However, the APOE $\varepsilon 4$ carrier status was not associated with EPS in our data, in line with previous reports. ${ }^{47}$ Lastly, we could not consider potential variables such as musculoskeletal diseases or physical pain that could influence on the movement symptoms.

In conclusion, our study demonstrated that baseline EPS in individuals with MCI are associated with a decreased risk of progression to $\mathrm{AD}$, but with a six folds increased risk of progression to dementia other than $\mathrm{AD}$. Thus, our results suggest that careful assessment of EPS in patients with incident MCI can yield important clinical information for prognosis.

\section{Acknowledgments}

This study was supported by a grant of the Korea Healthcare technology R\&D Project, Ministry of Health and Welfare, Republic of Korea (HI10C2020) and from the Samsung Medical Center Clinical Research Development Program (\#CRS106-32-2).

This research was also supported by a grant of the Research Driven Hospital R\&D project, funded by the CHA Bundang Medical Center (grant number: BDCHA R\&D 2017-029).

\section{REFERENCES}

1. Petersen RC. Mild cognitive impairment as a diagnostic entity. J Intern Med 2004;256:183-194.

2. Artero S, Ancelin ML, Portet F, Dupuy A, Berr C, Dartigues JF, et al. Risk profiles for mild cognitive impairment and progression to dementia are gender specific. J Neurol Neurosurg Psychiatry 2008;79:979-984.

3. Manly JJ, Tang MX, Schupf N, Stern Y, Vonsattel JP, Mayeux R. Frequency and course of mild cognitive impairment in a multiethnic commu- nity. Ann Neurol 2008;63:494-506

4. Luck T, Luppa M, Wiese B, Maier W, van den Bussche H, Eisele M, et al. Prediction of incident dementia: impact of impairment in instrumental activities of daily living and mild cognitive impairment-results from the German study on ageing, cognition, and dementia in primary care patients. Am J Geriatr Psychiatry 2012;20:943-954.

5. Palmer K, Backman L, Winblad B, Fratiglioni L. Mild cognitive impairment in the general population: occurrence and progression to Alzheimer disease. Am J Geriatr Psychiatry 2008;16:603-611.

6. Busse A, Hensel A, Guhne U, Angermeyer MC, Riedel-Heller SG. Mild cognitive impairment: long-term course of four clinical subtypes. Neurology 2006;67:2176-2185.

7. Petersen RC, Roberts RO, Knopman DS, Geda YE, Cha RH, Pankratz VS, et al. Prevalence of mild cognitive impairment is higher in men. The Mayo Clinic Study of Aging. Neurology 2010;75:889-897.

8. Ganguli M, Chang CC, Snitz BE, Saxton JA, Vanderbilt J, Lee CW. Prevalence of mild cognitive impairment by multiple classifications: The Monongahela-Youghiogheny Healthy Aging Team (MYHAT) project. Am J Geriatr Psychiatry 2010;18:674-683.

9. Mitchell AJ, Shiri-Feshki M. Rate of progression of mild cognitive impairment to dementia--meta-analysis of 41 robust inception cohort studies. Acta Psychiatr Scand 2009;119:252-265.

10. Farias ST, Mungas D, Reed BR, Harvey D, DeCarli C. Progression of mild cognitive impairment to dementia in clinic- vs community-based cohorts. Arch Neurol 2009;66:1151-1157.

11. Potter GG, Wagner HR, Burke JR, Plassman BL, Welsh-Bohmer KA, Steffens DC. Neuropsychological predictors of dementia in late-life major depressive disorder. Am J Geriatr Psychiatry 2013;21:297-306.

12. Turner AD, Capuano AW, Wilson RS, Barnes LL. Depressive symptoms and cognitive decline in older african americans: two scales and their factors. Am J Geriatr Psychiatry 2015;23:568-578.

13. Louis ED, Schupf N, Manly J, Marder K, Tang MX, Mayeux R. Association between mild parkinsonian signs and mild cognitive impairment in a community. Neurology 2005;64:1157-1161.

14. Louis ED, Tang MX, Schupf N, Mayeux R. Functional correlates and prevalence of mild parkinsonian signs in a community population of older people. Arch Neurol 2005;62:297-302.

15. Choi J, Myung W, Chung JW, Kang HS, Na DL, Kim SY, et al. Association between functional impairment, depression, and extrapyramidal signs in neuroleptic-free patients with Alzheimer disease. J Geriatr Psychiatry Neurol 2013;26:144-150.

16. Richards M, Stern Y, Mayeux R. Subtle extrapyramidal signs can predict the development of dementia in elderly individuals. Neurology 1993; 43:2184-2188.

17. Stern Y, Albert M, Brandt J, Jacobs DM, Tang MX, Marder K, et al. Utility of extrapyramidal signs and psychosis as predictors of cognitive and functional decline, nursing home admission, and death in Alzheimer's disease: prospective analyses from the Predictors Study. Neurology 1994;44:2300-2307.

18. Bennett DA, Beckett LA, Murray AM, Shannon KM, Goetz CG, Pilgrim $\mathrm{DM}$, et al. Prevalence of parkinsonian signs and associated mortality in a community population of older people. N Engl J Med 1996;334:7176.

19. Louis ED, Tang MX, Mayeux R. Parkinsonian signs in older people in a community-based study: risk of incident dementia. Arch Neurol 2004; 61:1273-1276.

20. Wilson RS, Schneider JA, Bienias JL, Evans DA, Bennett DA. Parkinsonianlike signs and risk of incident Alzheimer disease in older persons. Arch Neurol 2003;60:539-544.

21. Park HK, Na DL, Han SH, Kim JY, Cheong HK, Kim SY, et al. Clinical characteristics of a nationwide hospital-based registry of mild-to-moderate Alzheimer's disease patients in Korea: a CREDOS (Clinical Research Center for Dementia of South Korea) study. J Korean Med Sci 2011;26:1219-1226.

22. Kim S, Kim MJ, Kim S, Kang HS, Lim SW, Myung W, et al. Gender dif- 
ferences in risk factors for transition from mild cognitive impairment to Alzheimer's disease: A CREDOS study. Compr Psychiatry 2015;62: 114-122.

23. Ahn HJ, Chin J, Park A, Lee BH, Suh MK, Seo SW, et al. Seoul Neuropsychological Screening Battery-dementia version (SNSB-D): a useful tool for assessing and monitoring cognitive impairments in dementia patients. J Korean Med Sci 2010;25:1071-1076.

24. Morris JC. The Clinical Dementia Rating (CDR): current version and scoring rules. Neurology 1993;43:2412-2414.

25. American Psychiatric Association. Diagnostic and Statistical Manual of Mental Disorders Text Revision: DSM-IV-TR. Washington, DC: American Psychiatric Association; 2000.

26. Moon SY, Na DL, Seo SW, Lee JY, Ku BD, Kim SY, et al. Impact of white matter changes on activities of daily living in mild to moderate dementia. Eur Neurol 2011;65:223-230.

27. Noh Y, Lee Y, Seo SW, Jeong JH, Choi SH, Back JH, et al. A new classification system for ischemia using a combination of deep and periventricular white matter hyperintensities. J Stroke Cerebrovasc Dis 2014;23: 636-642.

28. Ye BS, Chin J, Kim SY, Lee JS, Kim EJ, Lee Y, et al. The heterogeneity and natural history of mild cognitive impairment of visual memory predominant type. J Alzheimers Dis 2015;43:143-152.

29. Folstein MF, Folstein SE, McHugh PR. "Mini-mental state". A practical method for grading the cognitive state of patients for the clinician. J Psychiatr Res 1975;12:189-198.

30. Bae JN, Cho MJ. Development of the Korean version of the Geriatric Depression Scale and its short form among elderly psychiatric patients. J Psychosom Res 2004;57:297-305.

31. McKhann G, Drachman D, Folstein M, Katzman R, Price D, Stadlan EM. Clinical diagnosis of Alzheimer's disease: report of the NINCDSADRDA Work Group under the auspices of Department of Health and Human Services Task Force on Alzheimer's Disease. Neurology 1984;34: 939-944.

32. Roman GC, Tatemichi TK, Erkinjuntti T, Cummings JL, Masdeu JC, Garcia JH, et al. Vascular dementia: diagnostic criteria for research studies. Report of the NINDS-AIREN International Workshop. Neurology 1993;43:250-260.

33. Erkinjuntti T, Inzitari D, Pantoni L, Wallin A, Scheltens P, Rockwood K, et al. Research criteria for subcortical vascular dementia in clinical trials. J Neural Transm Suppl 2000;59:23-30.

34. Grambsch PM, Therneau TM. Proportional hazards tests and diagnos- tics based on weighted residuals. Biometrika 1994;81:515-526.

35. Bae JB, Kim YJ, Han JW, Kim TH, Park JH, Lee SB, et al. Incidence of and risk factors for Alzheimer's disease and mild cognitive impairment in Korean elderly. Dement Geriatr Cogn Disord 2015;39:105-115.

36. Israeli-Korn SD, Massarwa M, Schechtman E, Strugatsky R, Avni S, Farrer LA, et al. Mild cognitive impairment is associated with mild parkinsonian signs in a door-to-door study. J Alzheimers Dis 2010;22:10051013.

37. Kim KW, Park JH, Kim MH, Kim MD, Kim BJ, Kim SK, et al. A nationwide survey on the prevalence of dementia and mild cognitive impairment in South Korea. J Alzheimers Dis 2011;23:281-291.

38. Solfrizzi V, Panza F, Colacicco AM, D'Introno A, Capurso C, Torres F, et al. Vascular risk factors, incidence of MCI, and rates of progression to dementia. Neurology 2004;63:1882-1891.

39. Burns JM, Galvin JE, Roe CM, Morris JC, McKeel DW. The pathology of the substantia nigra in Alzheimer disease with extrapyramidal signs. Neurology 2005;64:1397-1403.

40. Baba M, Nakajo S, Tu PH, Tomita T, Nakaya K, Lee VM, et al. Aggregation of alpha-synuclein in Lewy bodies of sporadic Parkinson's disease and dementia with Lewy bodies. Am J Pathol 1998;152:879-884.

41. Kish SJ, Chang LJ, Mirchandani L, Shannak K, Hornykiewicz O. Progressive supranuclear palsy: relationship between extrapyramidal disturbances, dementia, and brain neurotransmitter markers. Ann Neurol 1985;18:530-536.

42. Stern Y. Cognitive reserve in ageing and Alzheimer's disease. Lancet Neurol 2012;11:1006-1012.

43. Stern Y, Albert S, Tang MX, Tsai WY. Rate of memory decline in AD is related to education and occupation: cognitive reserve? Neurology 1999; 53:1942-1947.

44. Ye BS, Seo SW, Cho H, Kim SY, Lee JS, Kim EJ, et al. Effects of education on the progression of early- versus late-stage mild cognitive impairment. Int Psychogeriatr 2013;25:597-606.

45. O'Brien JT. Clinical significance of white matter changes. Am J Geriatr Psychiatry 2014;22:133-137.

46. Satagopan JM, Ben-Porat L, Berwick M, Robson M, Kutler D, Auerbach $\mathrm{AD}$. A note on competing risks in survival data analysis. Br J Cancer 2004;91:1229-1235.

47. Lopez OL, Kamboh MI, Becker JT, Kaufer DI, DeKosky ST. The apolipoprotein E epsilon 4 allele is not associated with psychiatric symptoms or extrapyramidal signs in probable Alzheimer's disease. Neurology 1997;49:794-797. 